\title{
Understanding student use of twitter and online forums in higher education
}

\author{
Eleanor J. Dommett ${ }^{1,2}$
}

Received: 20 April 2018 / Accepted: 11 July 2018 /Published online: 19 July 2018

(C) The Author(s) 2018

\begin{abstract}
The aim of this study was to better understand how students use online forums and Twitter in undergraduate learning. Students completed an anonymous online survey ( $N=50,54 \%$ completion rate) to assess their general approach to these tools, the types of interaction experienced and specific uses. Students were also asked to relate their use to categories of learning outcomes and rate the importance of different factors in using each tool. The study demonstrates more students use forums than Twitter but that both tools provide support for learning outcomes aimed at increasing knowledge and understanding and key skills. Furthermore, they do this differently; Twitter provides access to news media and those outside their programme whilst forums support discussion with peers. Different factors predicted how highly each tool was rated but in most cases, a key factor was whether students felt that use of a tool would increase their grade, indicating that assessment outcomes are strongly linked to use of both tools, despite them differing in terms of interactions and specific uses. The study has several limitations including a relatively small sample size and lack of detail about exact types of resources accessed and forum structures used.
\end{abstract}

Keywords Undergraduate $\cdot$ Learning outcomes $\cdot$ Social media $\cdot$ Twitter $\cdot$ Online discussion forums

\section{Background}

The advent of the internet and the various technological tools that have arisen as a consequence of it, have increased the ability we have to support and expand social learning, that is socially constructed learning that arises through participation in

Eleanor J. Dommett

Eleanor.dommett@kcl.ac.uk

1 Department of Psychology, Institute of Psychiatry, Psychology and Neuroscience, King's College London, London SE5 8AF, UK

2 Centre for Technology Enhanced Learning, Waterloo Bridge Wing, Franklin-Wilkins Building, 150 Stamford Street, London SE1 9NH, UK 
dialogue and interactions with others (Seely Brown and Adler 2008). There are currently a range of online tools available to support this participation. One such tool is the asynchronous online discussion forum, a tool frequently embedded within institutional virtual learning environments, and is most commonly aligned to social constructivist approaches to learning including collaborative learning, resource-based learning and problem based learning (Hammond 2005; Macdonald and Twining 2002) and conversational learning (Laurillard 1999) Indeed, the degree of activity within an online forum is considered to be a good indicator of the level of engagement in socioconstructivist pedagogies (Macfadyen and Dawson 2010). However, the use of forums are also thought to align with cognitivism pedagogy by providing an environment to stimulate cognitive learning strategies and critical thinking (Jonassen 1994). The exact pedagogic approach underpinning forum use is likely to depend, in part, on the type of forum used. There are thought to be several different types of forum: i) open - learners participate freely on a loosely-guided agenda ii) loosely-structured - learners complete specific tasks individually and share on the forum, and iii) cooperative task-based learners work in small teams using the forum to complete an assignment (Hammond 2005). These different types of forums can support different approaches to learning.For example, for open forums, participation may be limited to asking for information and, therefore, although the learner is technically participating, the intention could still be knowledge acquisition and social learning may be minimal. If forum use is collaborative, learners can become actively engaged in course content and peer interactions as they construct knowledge (Markel 2001). However, knowledge construction does not only arise when working collaboratively. Thomas (Thomas 2002) explored knowledge construction through forum posts on a module using loosely-structured forums and showed that learners' posts shift from those demonstrating pre-structural knowledge to extended abstract knowledge according to the SOLO taxonomy developed by Biggs and Collis (Biggs and Collis 1982). One of the main advantages of using online forums is that responses can be very fast if sufficient students are engaged with the tool (Hew 2016; Markel 2001). Furthermore, research demonstrates that forum activity is a reliable predictor of academic performance (Dawson 2010; Morris, Finnegan, \& Wu, 2005).

It is clear from the examples above that forums do have the potential to support learning, but they are not without their drawbacks. For example, it has been shown that there is a tendency for practitioners to dominate discussions (Sclater et al. 2016) and yet to be effective in supporting learning, this must be balanced with being responsive to learners (Markel 2001). There is also evidence from an in-depth analysis of practitioner and learner engagement that some types of practitioner engagement (e.g. self-referential posts) negatively impact on learner engagement (Pilotti et al. 2017). Another limitation of forums is that it is often difficult to maintain engagement without embedding their use in assessment, a problem that is noted for other media (Thomas 2002).

Twitter is a form of microblogging; a cross between instant messaging and blogging that allows users to share small pieces of information. Unlike asynchronous online discussion forums, Twitter is less often embedded into institutional virtual learning environments and there has been less research directly linking it to specific pedagogic approaches. However, in much the same way forums are aligned with participatory and social constructivist approaches to learning, Twitter can also be viewed in this way (Gao et al. 2012; Prestridge 2014). In addition, it has been considered in terms of the connected learning theory, that is the idea that all learning is informed and empowered 
by the information age (Ito et al. 2013). Although Twitter is not typically embedded in institutional virtual learning environments, in recent years it has impacted significantly on higher education, with $56 \%$ of 1400 faculty members considering Twitter a learning tool (Dhir et al. 2013). Exactly how Twitter is used varies considerably. At an institutional level, tweets are normally informational (Kimmons et al. 2017) e.g. 'Our next open day is in August' but a small proportion $(\sim 10 \%)$ are action tweets requiring a certain response e.g. 'Join us for the next open day'. However, the use of Twitter for teaching is normally conducted at module or programme level. Within this context it is suggested that Twitter can be used for i) giving organisational information ii) collaborative group work iii) sharing relevant resources iv) a research tool v) networking vi) surveying learners, and vii) producing content (Norman 2016). Junco et al. adds to this the ability to continue in-class discussions, a place for learners to ask questions and a space for learners to join up (Junco et al. 2011).

Although research to date into the use of Twitter is limited some studies have identified strengths of using this technology. Firstly, learners report that its use is beneficial because of increased connectedness with other learners meaning that they are less reliant on the lecturer, indicative of Twitter supporting independent learning (Chawinga 2017; Dhir et al. 2013). Secondly, it allows learners to participate effectively in course discussion (Chawinga 2017) by creating i) continuous and transparent communication between practitioners and learners ii) information learning and communication iii) social and transparent group work, and iv) a space for learners to express views without restriction (Dhir et al. 2013). Thirdly, and similar to forums, Twitter results in rapid responses (Chawinga 2017; Ricoy and Feliz 2016). Finally, it has been suggested that Twitter supports a culture of critiquing content (Conole and Alevizou 2010), not least because of the character limitation with learners stating that "Twitter made me think critically as I knew [that] inappropriate tweeting could distort the meaning of my post" (Chawinga 2017, p.12). Despite these reported strengths of Twitter, it is not without its weaknesses. Whilst many of these can be associated with general web-based applications, such as a need for appropriate internet access, some are specific to Twitter. For example, it has been noted that $36 \%$ of learners received no initial training on Twitter (Chawinga 2017). Additionally, much like forums, sustained engagement with Twitter appears to be assessment dependent with Junco et al. commenting that spikes in activity always occurred near deadlines (Junco et al. 2011). Given the potential for both learning tools to support learning effectively, this study aimed to better understand how students were currently using the different tools and to evaluate what factors may predict how highly they rate Twitter and forums as learning tools.

\section{Method}

\subsection{Participants and procedure}

A cross sectional design was used to examine how students were currently using forums and twitter and to evaluate what factors may predict how highly they rate them. Eligible participants - i.e., full-time undergraduates at a UK university, aged 18 years or over -completed an online survey. The study was advertised via email circulars to 
students at the host institution. Consenting participants were granted access to the online questionnaire, which took approximately thirty minutes to complete. Those who completed the questionnaire were offered entry into a prize draw for a $£ 30$ Amazon voucher. All procedures were approved by institutional Research Ethics Subcommittee (MR/16/17-1361). Of 93 participants who started the questionnaire, 43 failed to complete, yielding a final sample of 50 participants. Students were largely within their first $(38 \%)$, second $(26 \%)$ or third $(30 \%)$ year of study but there were also a small number in later years (fifth, 4\%; sixth $2 \%$ ). Students were studying thirty different degree courses, ranging from American Studies and Music to Dentistry and Medicine. Most degree courses were represented only by individual participants, but medicine and psychology were heavily represented with eight medical students and twelve psychology students.

\subsection{Understanding forum use}

Forum user status To understand how participants were using forums they were first asked whether they had used forums to support their learning during their undergraduate studies (Yes/No). If participants responded that they had used forums in this way they were asked whether their use of forums was part of the formal teaching directly supported by teaching staff, independent study or both. They were then asked to select statement(s) that best described the types of forums they used ('I use the online forums provided by my university', 'I use online forums associated with my course on social media (e.g. Facebook)', 'I use online forums with no association to my course or university').

Forum interactions Participants reporting that they had used forums for their studies were asked to rate the frequency with which they engaged in student-teacher, studentstudent and student-other interactions by selecting from 'Always, 'Often', 'Sometimes', 'Occasionally' and 'Never'.

Forum uses Participants reporting that they had used forums for their studies were asked to rate the frequency, by selecting from 'Always, 'Often', 'Sometimes', 'Occasionally' and 'Never', that they used them for the following purposes: i) To access additional learning material provided by my university teachers ii) To access additional learning material provided by my fellow students iii) To access additional learning material provided by others iv) To find relevant news/media articles v) To participate in a discussion around a topic within the module vi) To help me with assessment on a module vii) To check for administrative information (e.g. timetabling change) viii) To obtain or offer peer support ix) Other (option to specify).

Forum use and learning outcomes Participants reporting previous use of forums were given definitions of four distinct areas of learning outcomes as follows: Knowledge and Understanding (KU- learning outcomes normally requiring students to demonstrate or explain knowledge of key concepts or theories), Cognitive Skills (CS Cognitive skills - learning outcomes normally requiring students to demonstrate particular abilities, for example, using data or recognizing limitations of a particular 
approach), Key Skills (KS, learning outcomes normally relating to study skills such as locating information online or communication skills), Professional and Practical Skills (PPS, learning outcomes relating to professional practice in some way, for example, for a scientist, this may be designing and conducting an experiment). They were then asked to indicate whether they had used forums to support these different types of learning outcomes (Yes/No). Where they had done so they were then asked to rate the effectiveness of forums in supporting the specific types of learning outcomes ('Extremely effective', 'Very effective', 'Moderately effective', 'Slightly effective', 'Not effective at all').

Factors influencing use of forums Irrespective of whether students had previously used forums for learning they were asked to rate their agreement with the statement 'I would rate the use of forums for learning very highly', choosing from 'Strongly agree, 'Agree', 'Somewhat agree', 'Neither agree nor disagree', 'Somewhat disagree', 'Disagree', 'Strongly disagree'. They were then asked to rate, using the same scale their agreement with the following statements about the impact of using forums. Note that the phrasing was adjusted to reflect those currently using it and those not currently using it: i) Skills in working with other students are/can be improved when using forums as part of my studies ii) Skills in working with teaching staff are/can be improved when using forums as part of my studies iii) It is/could be more comfortable using forums to discuss sensitive or controversial issues iv) I do/ could understand the material better using forums v) I do/could feel more comfortable asking questions when I do not understand the material using forums vi) I think the integration of forums into my studies makes/could make the module more enjoyable vii) Using forums has/could help me consider differing points of view vii) I think using forums has/could improve my grades. Finally, all students were asked to rate the importance of the following factors in using forums, by selecting from 'Extremely important', 'Very important', 'Moderately important', 'Slightly important', 'Not at all important': i) expectation of other students, ii) expectation of teaching staff, iii) knowledge that other students read posts iv) knowledge that teaching staff read posts v) knowledge that teaching staff write posts vi) efficiency of communicating with a large group vii) directly supporting learning outcomes.

\subsection{Understanding twitter use}

The same approach was taken to understanding the use of Twitter to that outlined above, i.e. current users were asked several additional questions, but all participants were asked about factors that could underlie use of the technology. The only distinction was where participants had used Twitter they were then asked to select a statement that best described their approach to Twitter accounts for study use ('I have a single twitter account and only use it for study-related purposes', 'I have a single twitter account and use it for study and personal purposes', 'I have multiple twitter accounts but do not distinguish between them in terms of purpose', 'I have multiple twitter accounts, keeping at least one for study-related purposes only') rather than the question in forums about the type of forums used. 


\subsection{Data analysis}

\subsubsection{Comparing tools}

The User Status for each tool was analysed with a Chi-Square analysis to determine whether there was a relationship between use of the two tools. In addition, the ratings for Twitter and forums as online learning tools from all participants were compared using a paired-samples t-test.

\subsubsection{Individual tools}

Measures of 'Twitter/Forum User Status', 'Twitter/Forum Interactions', 'Twitter/Forum Uses' and 'Twitter/Forum use and learning outcomes' were converted into percentages. For factors influencing use of each tool, Pearson's correlations between each the predictor variables i.e. each factor and overall rating for that tool identified significant correlates $(p$ $<.05$ ), which were subsequently entered into a multiple regression model. To achieve the most parsimonious predictive model, backwards stepwise elimination was used, whereby redundant predictors are systematically removed from the model, until further refinement is not possible without losses in predictive utility. All regression model assumptions were met (Field 2013): no multicollinearity or singularity was observed among predictors at any stage within the backwards model, with all tolerance values were below 0.2 or 0.1 , and all variance inflation factor scores approximating 1 , and none above 10 . The amount of variance explained is reported using adjusted R-square to give the ratio of predictor variables to sample size (Tabachnick and Fidell 2007). Separate regression analyses were conducted for those currently using each tool and those not using it. Additionally, scores on each factor and the rating of the technology were compared between users and nonusers using an independent samples t-test (with the Bonferroni correction applied for multiple comparisons to give a critical $p=.0033$ ).

\section{Results}

\subsection{Comparison of tools}

Of the 50 students completing the survey, only $26 \%(N=13)$ reported using Twitter to support learning during their undergraduate studies in comparison to $42 \%(N=21)$ reporting using forums. Chi-Square analysis revealed there was no significant association between use of the two technologies $\left(\chi^{2}(1)=.124, p=.724\right)$ meaning that whether a student engaged with one tool did not relate to whether they used the other. Overall ratings for Twitter and forums as learning tools did differ significantly $(\mathrm{t}(45)=2.0418, p=.0471)$ with Twitter receiving significantly higher ratings (mean \pm $\mathrm{SEM}=4.64 \pm 0.23)$ in comparison to forums $(3.76 \pm 0.26)$.

\subsection{General approaches to using forums}

Of the 21 students who had previously used online forums to support learning, for the majority $(42.9 \%)$ of students this forum use was part of both formal teaching and 
independent learning, whilst $38.1 \%$ reported only using them as part of formal teaching and $19.0 \%$ using them exclusively for independent study. Of those using forums $80.9 \%$ report using forums provided by the university, whilst $71.4 \%$ reported using forums on social media associated with their course e.g. Facebook groups and $42.9 \%$ report using forums that have no association to their programme or course.

When asked about the types of interactions they engaged with on forums the around one quarter reported never interacting with teaching staff $(28.6 \%)$ or others $(25.0 \%)$ (Fig. 1) whilst only $4.8 \%$ reported no interaction with their peers. The most common type of interaction was with peers, with $62 \%$ engaging in this type of interaction always or often.

Examining the types of uses students reported for forums shows that the most common uses, where students report using forums often or always, were module discussions $(57.1 \%)$, accessing additional material from peers $(52.4 \%)$ and assessment support $(52.4 \%)$. The least common uses were to access additional material from others $(38.1 \%)$ or to find relevant news/media information (42.8\%) (Fig. 2).

Students were asked to indicate whether they had used forums to support specific types of learning outcomes. The majority $(90.5 \%)$ had used forums to support knowledge and understanding, for development of key skills $(87.5 \%)$ and cognitive skills $(87.5 \%)$. Fewer students reported use for professional and practice skills learning (71.4\%). Of those using forums to support a specific type of learning outcome, the ratings of effectiveness varied considerably. For knowledge and understanding, all students felt it had some degree of effectiveness (63.1\% Extremely effective; $31.6 \%$ Very effective and 5.2\% Moderately effective). A similar pattern was found for key skills (27.8\% Extremely effective; 33.3\% Very effective and 33.3\% Moderately effective; $5.6 \%$ Somewhat effective). However, for cognitive skills a small percentage did find forum use to be not all effective $(5.6 \%)$ with the remainder seeing it as having a range of degrees of effectiveness (27.8\% Extremely effective, 38.9\% Very effective, $16.7 \%$ Moderately effective, $11.1 \%$ Slightly effective). A similar pattern was found for professional and practice skills (26.7\% Extremely effective, $26.7 \%$ Very effective, 26.7\% Moderately effective, $6.7 \%$ Slightly effective, $13.3 \%$ Not at all effective).

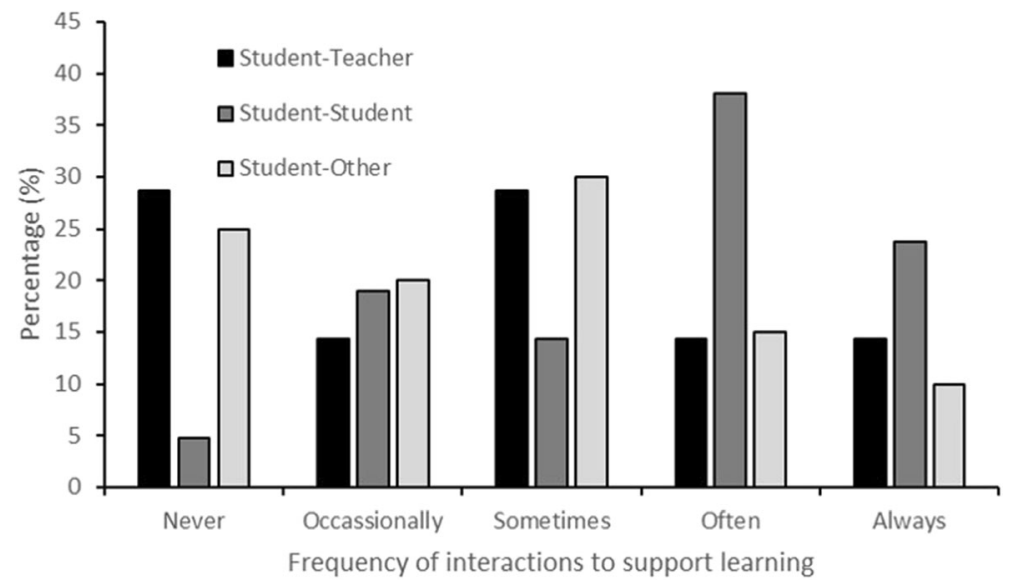

Fig. 1 Reported frequency of interactions on forums for current forum users 


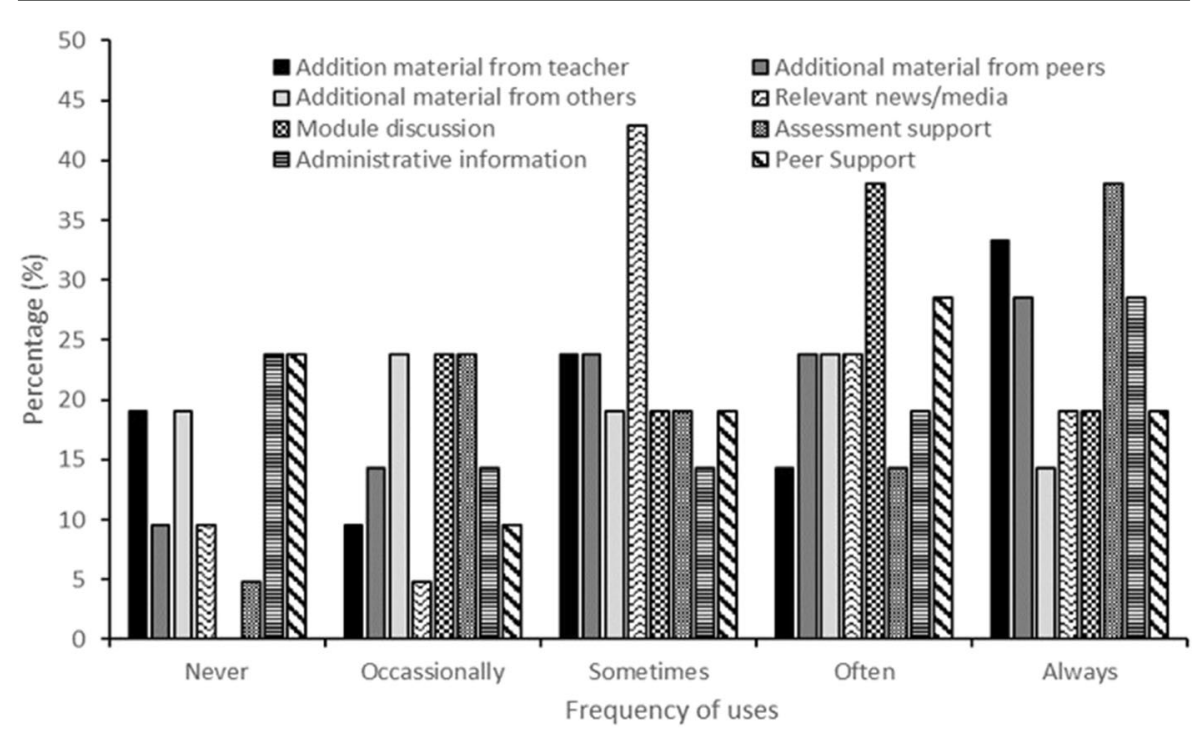

Fig. 2 Reported uses of forums for current forum users

\subsection{Factors predicting forum use in current users}

Correlation and backward regression were conducted on the factors that may predict the overall rating of forums for learning. Significant correlations were found for only two factors 'Enjoyable to use 'Improved grades' (Table 1). At the first step, a model comprising 'Improved grades' and 'Enjoyable to use' explained 50.5\% of variance in attitude towards forums $\left(\mathrm{R}^{2}=.505\right.$, Model F $\left.(2,18)=11.192, p=.001\right)$. No variables were removed. Within this model, 'Improved grades' $(\mathrm{B}=.527, p=.015)$ and 'Enjoyable to use' $(\mathrm{B}=.370, p=.034)$ were both positive predictors of ratings for using forums (Table 2).

\subsection{Factors predicting forum use in non-users}

Significant correlations were found between the overall rating of forums as a learning tool and i) Knowledge staff write posts ii) Supports learning outcomes iii) Skills working with peers iv) Skills working with staff v) Comfort on difficult issues vi) Improved understanding vii) Comfort asking questions viii) Enjoyable to use ix) Consideration of others views and $\mathrm{x}$ ) Improved grades (Table 3). At the first step, these variables explained $82.4 \%$ of variance in their rating of forums as a learning tool (Adjusted $\mathrm{R}^{2}=.824$, Model $\left.\mathrm{F}(10,28)=14.116, p<.001\right)$. Removing all variable except 'Comfort on difficult issues' and 'Improved grades' through a stepped process did not significantly improve the predictive power of the model but did create a more parsimonious model, whereby these final two variables accounted for $83.1 \%$ of the variance in forum ratings (Adjusted $\mathrm{R}^{2}=.831$, Model $\mathrm{F}(2,28)=70.033, \mathrm{p}<.001$ ) (Table 4).

Comparison of the ratings given by users and non-users showed that there were no significant differences between scores for any variable once the Bonferroni correction was applied. However, there were some differences where $p<.05$ is employed, noted 


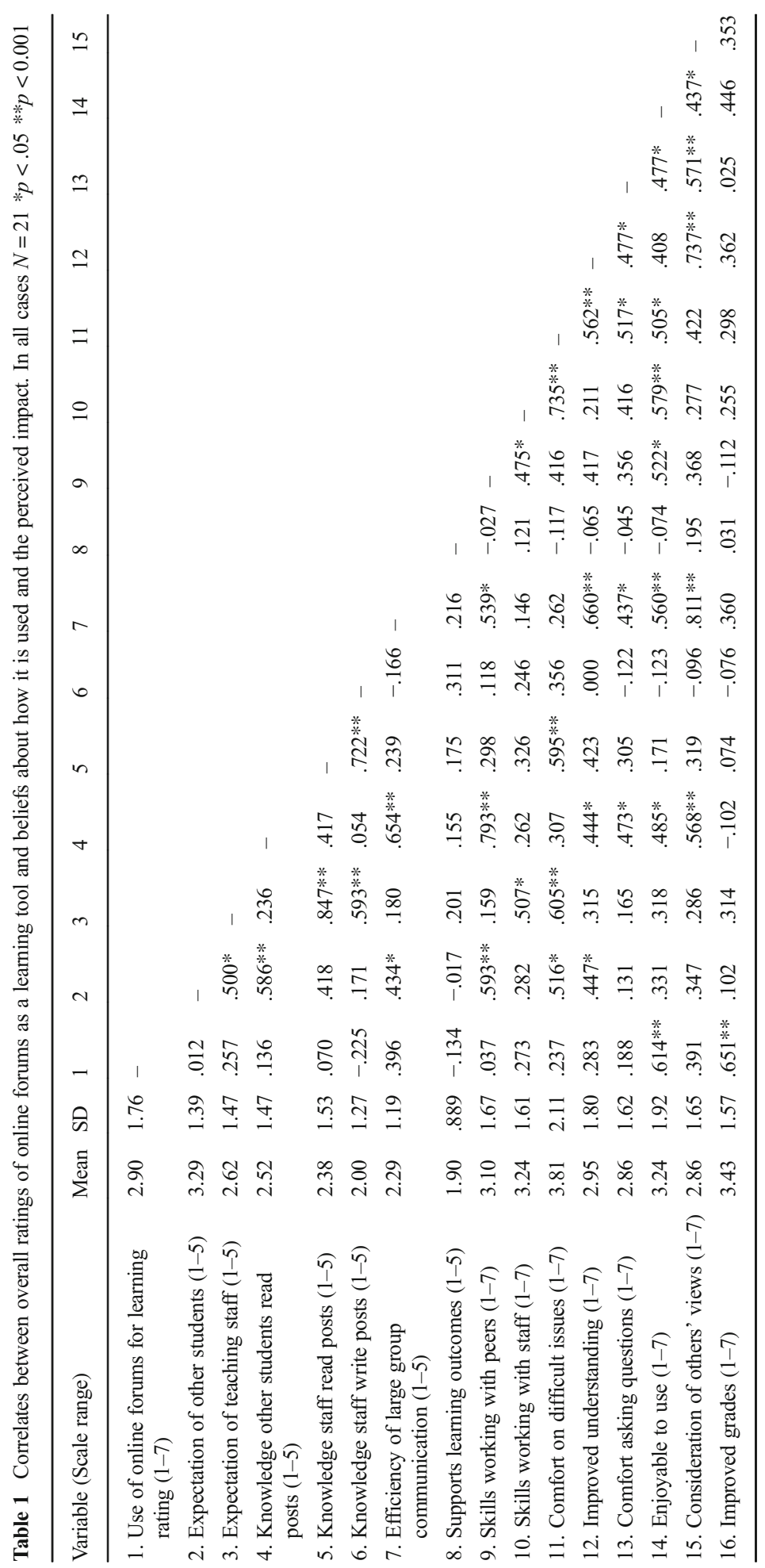


Table 2 Final multiple regression model: predictors of rating of forums as a learning tool. $* p<.05$

\begin{tabular}{llll}
\hline Final model & SE & B & $\beta$ \\
\hline Improved grades & .197 & .527 & $.470^{*}$ \\
Enjoyable to use & .161 & .370 & $.404^{*}$ \\
$\mathrm{R}^{2}$ & .554 & & \\
Model $F$ & 11.192 & & \\
\hline
\end{tabular}

because of the conservative nature of the correction. Non-users rated the likely improvements in working with others $(\mathrm{t}(48)=2.066, p=.044)$ and understanding different viewpoints ( $\mathrm{t}(48)=2.131, p=.038)$ more highly than users. They also gave an overall higher rating for forums as a learning tool $(\mathrm{t}(48)=2.668, p=.01)$.

\subsection{General approaches to using twitter}

Of the 13 students using Twitter to support their learning, most (92.3\%) reported that this had been part of their independent study rather than structured within their formal teaching $(7.7 \%)$. Most students $(92.3 \%)$ also reported having a single twitter account that they used for both personal and study purposes. Only one student (7.7\%) stated that they have multiple accounts, although they did not distinguish between them in terms of uses. When asked about the types of interactions they engaged with on twitter the majority (66.7\%) reported no interaction with teaching staff at all (Fig. 3) and around one third $(30.8 \%)$ reported no interaction with their peers. The most common type of interaction, which was engaged with often or always (38.5\% total) was with others outside of their programme.

This pattern of interaction is not particularly surprising when the main uses of Twitter are examined. The most common uses, where students indicate they engage with this use often or always were accessing relevant news/media information $(69.3 \%)$ or access additional material from others $(38.5 \%)$. This was followed by taking part in module discussions $(30.8 \%)$. The least common use was to obtain assessment support (7.7\%), additional material from their teacher $(15.4 \%)$ or administrative information (15.4\%) (Fig. 4).

Students were asked to indicate whether they had used Twitter for learning to support specific types of learning outcomes. Over three-quarters $(79.9 \%)$ had used twitter to support knowledge and understanding learning outcomes and $61.5 \%$ had used it for development of key skills. Fewer students reported use for professional and practice skills learning (53.8\%) and cognitive skills (46.1\%). Of those who reported using Twitter to support knowledge and understanding there was a range of beliefs about its effectiveness, with $30 \%$ stating it was extremely effective, $30 \%$ considering moderately effective and a further $30 \%$ considering it slightly effective and only $10 \%$ considering not effective at all. For cognitive skills $16.7 \%$ of those who had used it for the purpose felt it was moderately effective whilst the remaining $83.3 \%$ felt it only slightly effective. For key skills the majority of those using it felt it to be moderately effective $(62.5 \%)$ with the remaining equally split across very effective, slightly effective and not effective at all. Finally, for professional and practical skills, of those using it in this way the majority felt it was moderately effective $(71.4 \%)$ with the remaining equally split between extremely effective and not at all effective. 


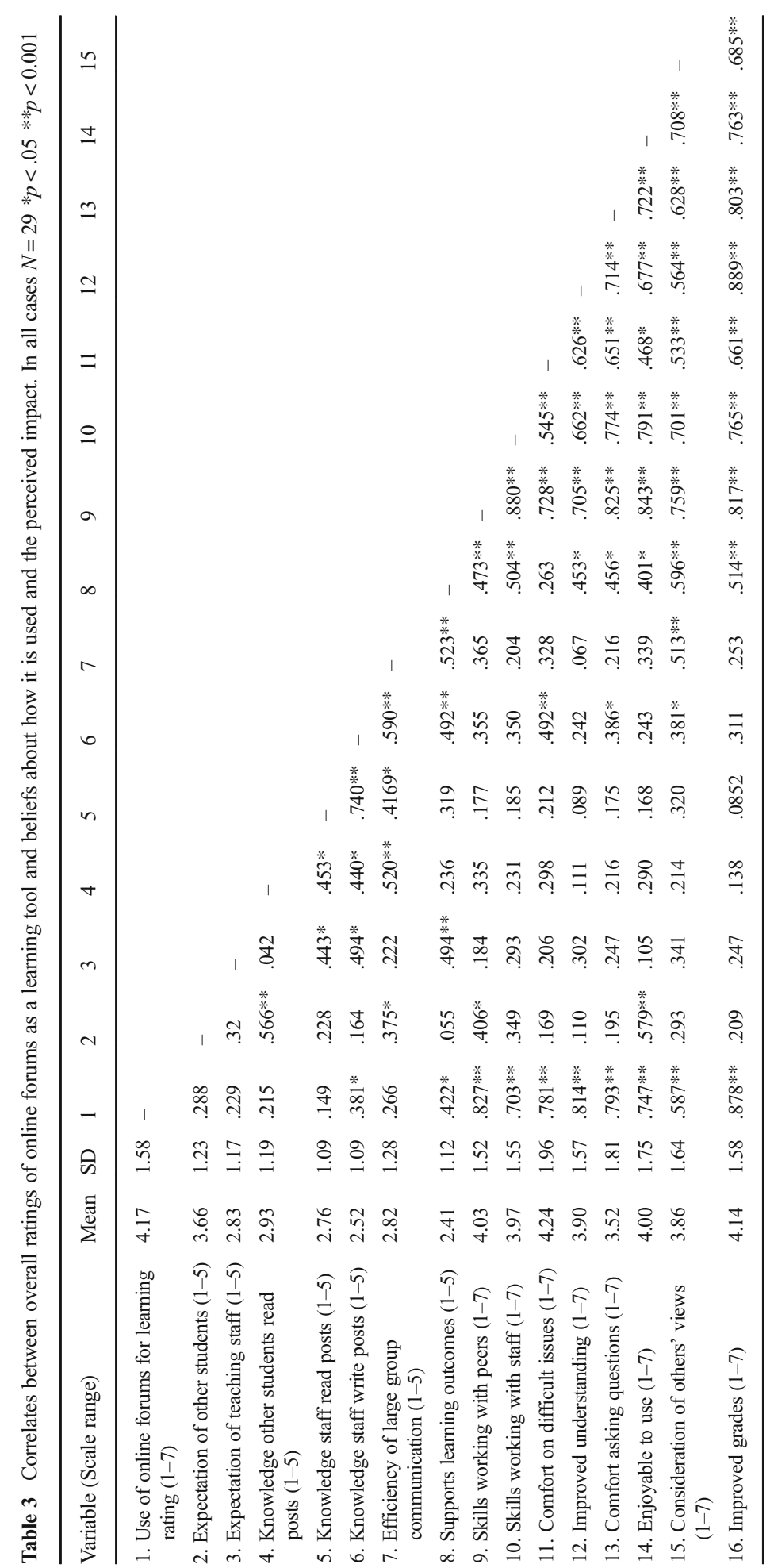


Table 4 Final multiple regression model: predictors of rating of forums as a learning tool. $* p<.01 * * p<.001$

\begin{tabular}{llll}
\hline Final model & $\mathrm{SE}$ & $\mathrm{B}$ & $\beta$ \\
\hline Comfort on difficult issues & .084 & .288 & $.357^{*}$ \\
Improved grades & .104 & .646 & $.643^{*}$ \\
$\mathrm{R}^{2}$ & .831 & & \\
Model $F$ & 70.033 & & \\
\hline
\end{tabular}

\subsection{Factors predicting twitter use in current users}

Pearson's correlations between each hypothesised predictor variable and the Twitter rating were identified (Table 5). Significant correlates $(p<.05)$ were used in a multiple regression model. At the first step, a model comprising 'Skills working with peers' and 'Enjoyable to use' explained $36.3 \%$ of variance in their rating of Twitter as a learning tool (Adjusted $\mathrm{R}^{2}=.363$, Model F $(2,10)=4.422, p=.042$ ). Removing 'Enjoyable to use' at the second step did not improve the predictive power of the model but created a more parsimonious model, which explained $41.7 \%$ of variance in rating (Adjusted $\mathrm{R}^{2}=.417, \mathrm{~F}$ change $=.064, p=.806$; Model F $\left.(2,10)=9.598, p=.010\right)$. Within this model, 'Skills working with peers' $(\mathrm{B}=.636, \mathrm{p}=.010)$ was a positive predictor of ratings for using twitter (Table 6).

\subsection{Factors predicting twitter use in non-users}

Significant correlations were found between the overall rating of Twitter as a learning tool and i) Knowledge other students read posts i) Efficiency of large group communication iii) Skills working with peers iv) Skills working with staff v) Comfort on difficult issues vi) Improved understanding vii) Comfort asking questions viii) Enjoyable to use ix) Consideration of others views and x) Improved grades (Table 7). These variables were therefore entered into a regression. At the first step, these variables explained $76.3 \%$ of variance in their rating of Twitter as a learning tool (Adjusted

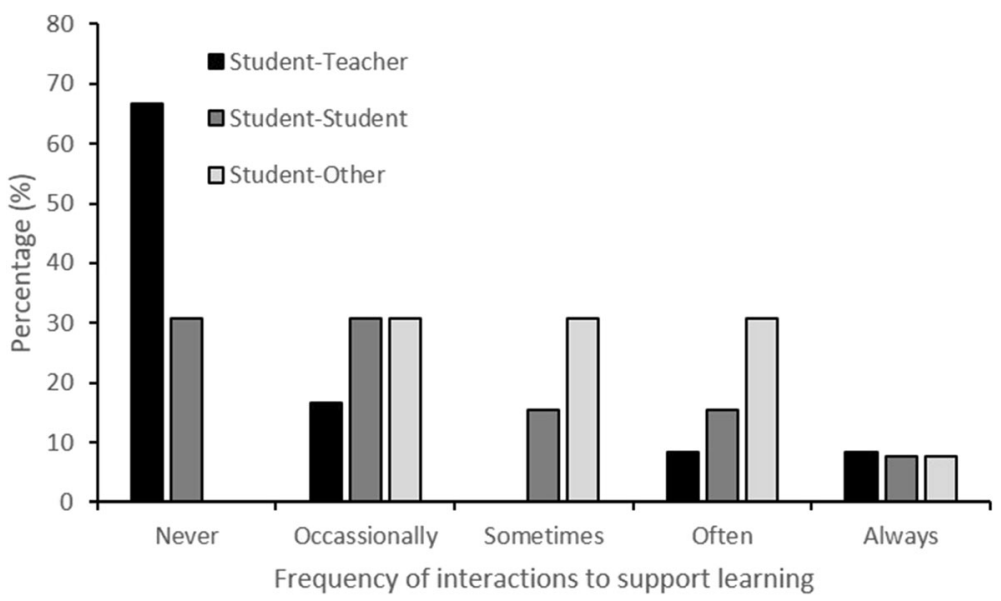

Fig. 3 Reported frequency of interactions on Twitter for current Twitter users 


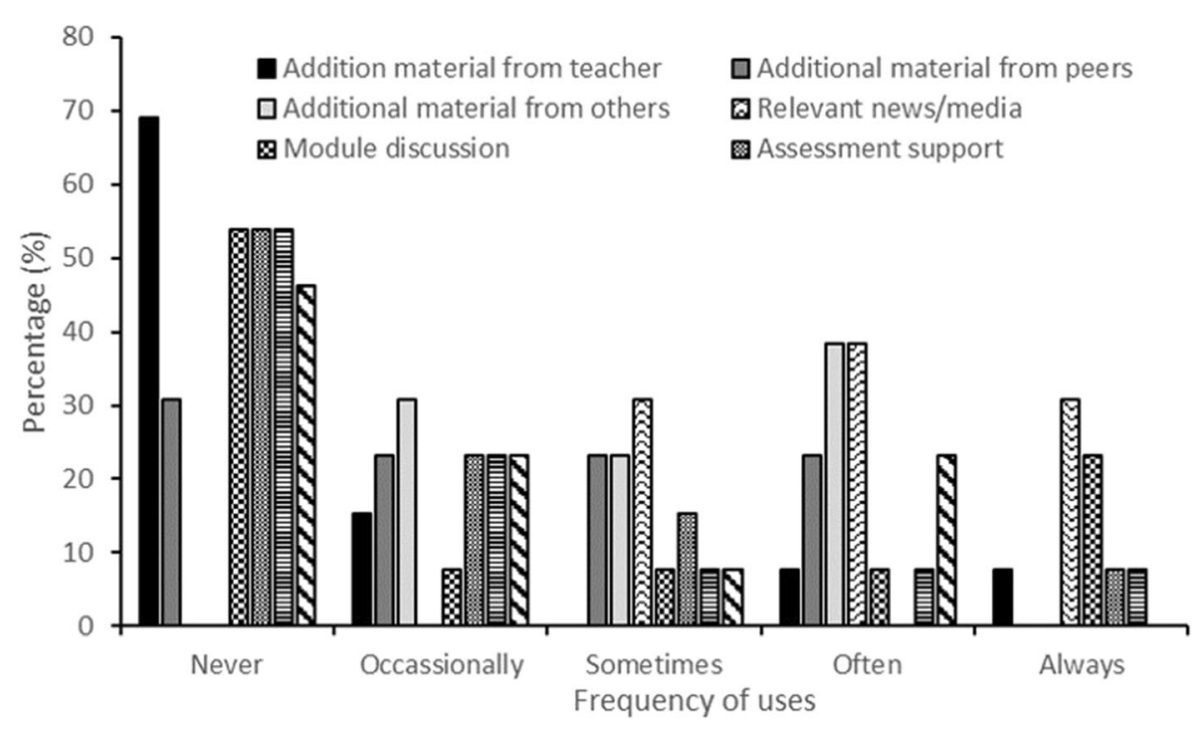

Fig. 4 Reported uses of Twitter for current Twitter users

$\mathrm{R}^{2}=.763$, Model $\left.\mathrm{F}(11,36)=11.539, p<.001\right)$. Removing posts i) Knowledge other students read posts ii) Efficiency of large group communication iv) Improved understanding v) Comfort asking questions vi) Enjoyable to use vii) Consideration of others views in subsequent did not improve the predictive power of the model but created a more parsimonious model containing only i) skills working with staff, ii) discussion of sensitive and controversial issues and iii) improve grades accounting for $80.1 \%$ of the variance in twitter rates (Adjusted $R^{2}=.801$, Model $F(3,33)=49.231$, $\mathrm{p}<.001)$ (Table 8).

Comparisons of the ratings given by users and non-users showed that there were no significant differences between scores for any variable once the Bonferroni correction was applied. Given the conservative nature of the correction, it is noteworthy that there were some differences where $p<.05$. Current Twitter users rated the importance of expectations of staff $(\mathrm{t}(48)=2.122, p=.039)$, the knowledge that staff read posts ( $\mathrm{t}(48)$ $=2.727, p=.009)$ and that staff wrote posts $(\mathrm{t}(48)=2.196, p=.0033)$ more highly than non-users.

\section{Discussion}

\subsection{Summary and interpretation}

As may be expected for a tool often built into the institutional virtual learning environment, a greater proportion of students were using forums than were found to use Twitter. Additionally, there was no relationship between use of the two tools, which could suggest that tools are not just routinely adopted by certain students. It is interesting to note that although fewer students used Twitter to support their learning, across all participants it was rated more highly by them. It is possible that the slightly higher rating is attributable to the novelty of using Twitter. This is partially supported 


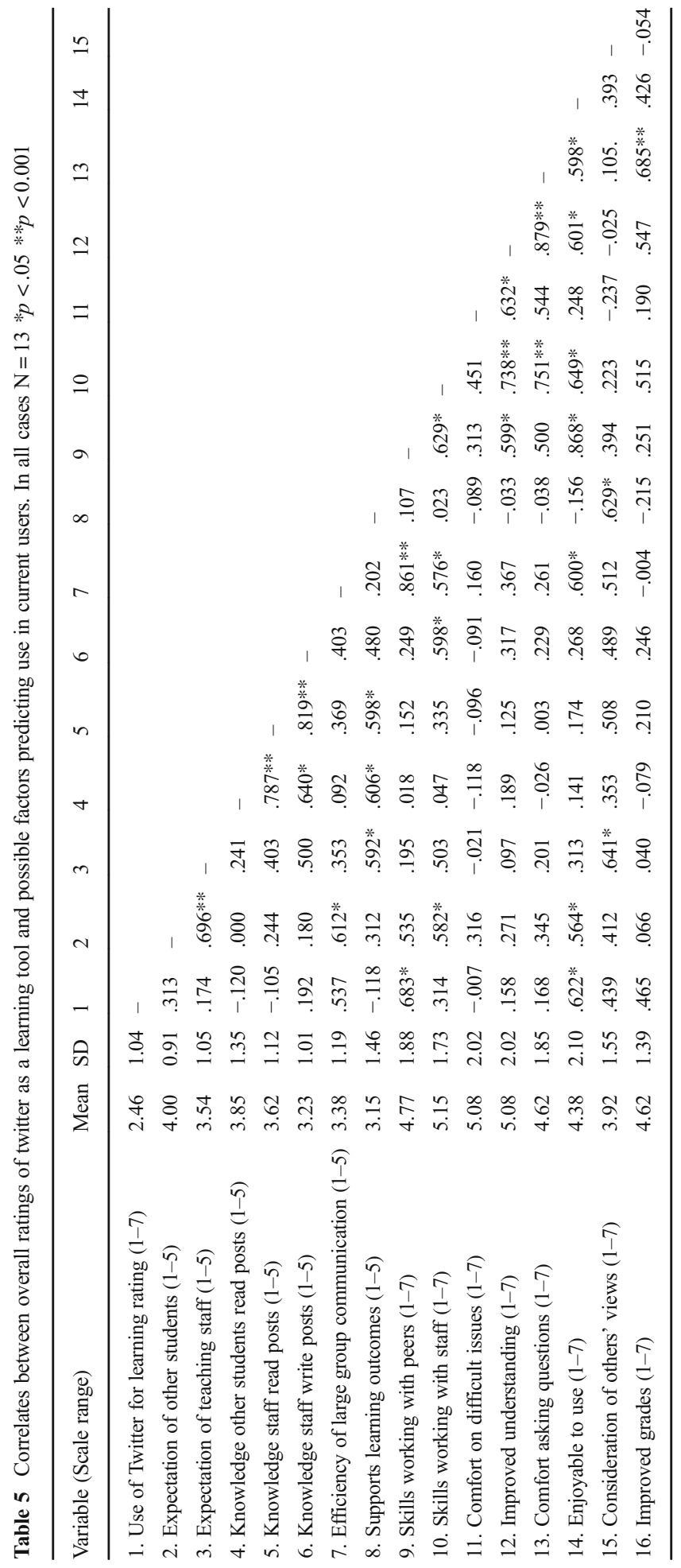


Table 6 Final multiple regression model: predictors of rating of Twitter as a learning tool in current users. $* * p=.01$

\begin{tabular}{llll}
\hline Final model & SE & B & $\beta$ \\
\hline Skills working with peers & .205 & .636 & $.683^{* *}$ \\
Adjusted $\mathrm{R}^{2}$ & .413 & & \\
Model $F$ & 9.598 & & \\
\hline
\end{tabular}

by examination of the ratings provided by users and non-users for each tool. Although there was no significant difference between ratings of the two groups, those using a technology generally rated it lower than those not doing so. Previous research has shown that sustained engagement is difficult to achieve (Thomas 2002), which may explain the lower ratings in current users. However, it has also been suggested that maintaining use of a tools such as these for learning requires clear pedagogical benefits to be realized (Nichols 2003). Therefore, it is possible to speculate that the slightly lower ratings found in those using them could indicate that these benefits are not present.

In terms of forum uses, in most cases students were using them for formal teaching or both formal and independent work. They most frequently reported using those provided by the university but there was also significant use of associated forums on social media. The most common type of interaction on forums was with their peers, which is in line with their reported uses, the most common of which was module discussions and accessing information from peers. The most marked contrast between the two tools was that whilst accessing relevant news or media items was the most frequent activity on Twitter, it was the least frequent on forums. Despite different uses of the tools, students felt that forums supported knowledge and understanding learning outcomes in a similar proportion to that reported for Twitter. The same was true of key skills. However, far more students felt that use of forums supported cognitive skills and professional and practice skills. It is possible to speculate that this was because the forums were being used far more for discussion purposes than was reported for Twitter. For current forum users the key factors predicting ratings of forums as learning tools were whether students believed they improved grades and whether they found them enjoyable to use. However, for those not currently using forums the most important factors in predicting their rating of forums as a learning tool were whether they felt comfortable discussing sensitive and controversial issues on forums and, again, whether their use improves grades. This suggests that a common feature for all students in whether they rate forums as learning tools was the relationship to their grades.. In the present study we did not assess the impact of forum use or twitter on grades, but previous research suggests that forum activity is a reliable indicator of academic performance (Dawson 2010; Morris, Finnegan, $\& \mathrm{Wu}, 2005)$. However, it is important to recognize that this relationship may vary with the type of forum used, something which was not reported in the current study.

Previous research has indicated that Twitter is having a significant impact on Higher Education and that over half of faculty members view Twitter as a learning tool (Dhir et al. 2013). Our results indicate that fewer students see Twitter as a learning with only $26 \%$ reporting using it for learning. Of those using it, they largely did so as part of their independent learning, which is in line with previous research, suggesting that they learn with less reliance of lecturers when using Twitter (Chawinga 2017). However, in contrast to previous work, students in the current study indicated that they were not interacting frequently with their peers (Dhir et al. 2013). By contrast the main interactions were taking 


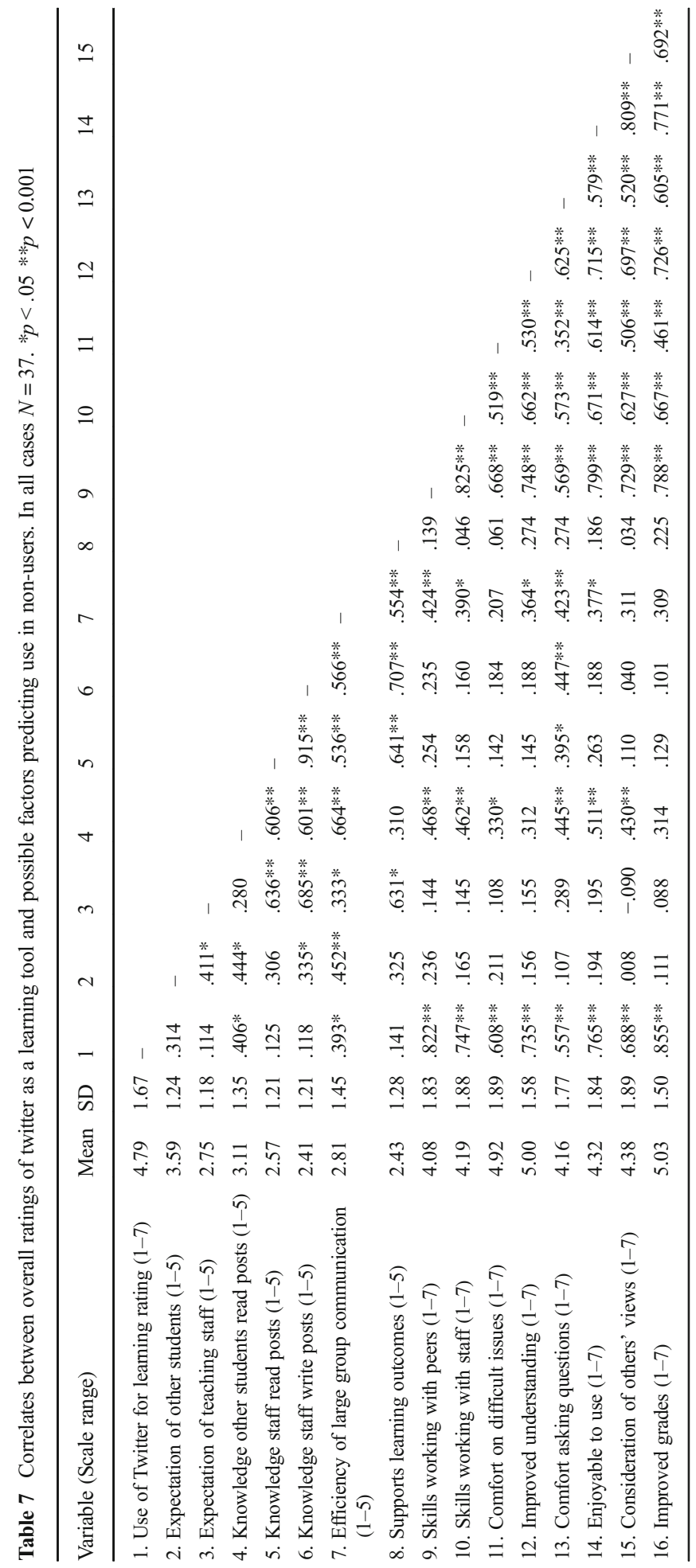


Table 8 Final multiple regression model: predictors of rating of Twitter as a learning tool in non-users. $* p<.05 * * p<.001$

\begin{tabular}{llll}
\hline Final model & SE & B & $\beta$ \\
\hline Skills working with teaching staff & .094 & .212 & $.239^{*}$ \\
$\begin{array}{l}\text { Comfortable discussing sensitive } \\
\quad \text { and controversial issues }\end{array}$ & .078 & .183 & $.207^{*}$ \\
$\quad$ Improve my grades & .113 & .670 & $.591^{* *}$ \\
Adjusted $\mathrm{R}^{2}$ & .801 & & \\
Model $F$ & 49.231 & & \\
\hline
\end{tabular}

place with those outside of their peer and teaching staff group. Much has been made in previous literature of the open and effective communication space provided by Twitter, making it a suitable tool for module discussions (Chawinga 2017; Dhir et al. 2013). However, the present data shows that less than one third of students used Twitter for this purpose, in contrast to almost $70 \%$ using Twitter to find relevant news or media stories for their studies. This use of seeking information is in line with the fact that almost $80 \%$ reported using Twitter to support knowledge and understanding learning outcomes and around $62 \%$ reported using it to develop key skills, which, of course, includes locating information online. Interestingly, the type of learning outcome least likely to be supported with Twitter use was cognitive skills, which had been identified as an area well supported by Twitter (Chawinga 2017; Conole and Alevizou 2010; Ricoy and Feliz 2016). This previous work suggested that Twitter supported critical thinking and improved communication skills. The latter was believed to be in part due to the limited character count. It is possible that the increase in character count that occurred in November 2017 i.e. as this data was being collected could have impacted on it. However, in the present study students were not asked to disclose how frequently they were writing posts but rather just using Twitter and therefore it is also possible the participants of the current study were not prolific posters of tweets but rather consumers of them. In line with the emphasis on key skills, which includes communication skills, the only significant predictor of Twitter ratings in current users was whether they believed using Twitter enhanced their skills in working with peers. This is, however, slightly at odds with their pattern of interaction which did not suggest interactions with peers in many cases. By contrast, Twitter ratings were predicted by more variables when non-users were asked to rate certain factors. Twitter was more likely to be rated highly as a learning tool by those who believed it would improve their skills working staff, be a comfortable place to discuss sensitive and controversial issues and improve their grades. The latter two were also found to predict ratings for forums as learning tools in non-user, suggesting that they may be important to students irrespective of the tool under investigation. For both Twitter and forums, different predictors could be found in current and non-users which could suggest that neither tool is reaching its full potential. Alternatively, it is possible that this discrepancy arises because the students have unrealistic expectations of what the tools offer. It would, therefore, be of interest to better understand what student think these tools may offer and what they actually experience.

Based on the findings here, it is possible to suggest some recommendations for universities or individual practitioners wishing to utilize forums or Twitter. Firstly, in both cases, the students already using the tools have identified that they are effective in supporting the development of knowledge and understanding and key skills and 
therefore, tasks that directly relate to these categories of learning outcomes may be well-received. Secondly, although both tools support similar learning outcomes they may do so in distinct ways and therefore not be interchangeable so learning activities should be designed with the strengths of the two in mind. For example, where students are required to find information from the news or general media, it may be that they are directed to using Twitter and then sharing their findings with their peers on forums as part of a module discussion. Thirdly, a key factor in predicting how favourably both tools will be viewed by non-users is whether they believe their use will improve their grades. Given that previous literature also suggests sustained use is only found when engagement is linked to assessment (Thomas 2002), it may be appropriate to incentivize use of the tools either by directly linking their use to assessment e.g. modelling the cooperative tasked-base use of forums (Hammond 2005) or through indirect links such as non-assessed module discussions, especially those around sensitive or controversial issues, which are likely to enhance student's knowledge of a topic.

\subsection{Limitations}

It is important recognize that there are several limitations to the present study. Firstly, the sample size of the study is small and was skewed towards those studying psychology or medicine and, therefore, the results may not generalize to the wider undergraduate population. Secondly, the nature of the quantitative data collected did not provide a full picture of how students use the two tools. For example, those using Twitter were not asked to indicate what kinds of news media they were consuming and whether they went on to retweet or disseminate the information in other ways. They were also not asked what kinds of forums they were using, although at this institution most forum use falls under the open forum (Hammond 2005). Thirdly, we did not collect data on demographic data that may impact on use of tools such as socioeconomic status or disabilities. Linked to this, although we collected data on the disciplines studied by students we were not able to differentiate these groups for analysis purposes and future studies may consider specific discipline comparisons. Finally, given there are no previously validated measures for collection of this data, our findings are based on currently unvalidated questionnaires. Whilst distribution of data was normal and question phrasing was clear and simple, use of previously validated questionnaire, where available, is preferable. Future research should consider a more in-depth analysis of users and non-users of the tools of interest, potentially combining quantitative and qualitative research.

\section{Compliance with ethical standards}

Conflict of interest The author declares that they have no conflict of interest.

Pulisher's Note Springer Nature remains neutral with regard to jurisdictional claims in published maps and institutional affiliations.

Open Access This article is distributed under the terms of the Creative Commons Attribution 4.0 International License (http://creativecommons.org/licenses/by/4.0/), which permits unrestricted use, distribution, and reproduction in any medium, provided you give appropriate credit to the original author(s) and the source, provide a link to the Creative Commons license, and indicate if changes were made. 


\section{References}

Biggs, J., \& Collis, K. (1982). The psychological structure of creative writing. Australian Journal of Education, 26(1), 59-70.

Chawinga, W. D. (2017). Taking social media to a university classroom: Teaching and learning using Twitter and blogs. International Journal of Educational Technology in Higher Education, 14(1), 3.

Conole, G., \& Alevizou, P. (2010). A literature review of the use of Web 2.0 tools in Higher Education. A report commissioned by the Higher Education Academy.

Dawson, S. (2010). 'Seeing'the learning community: An exploration of the development of a resource for monitoring online student networking. British Journal of Educational Technology, 41(5), 736-752.

Dhir, A., Buragga, K., \& Boreqqah, A. A. (2013). Tweeters on campus: Twitter a learning tool in classroom? Journal of Universal Computer Science, 19(5), 672-691.

Field, A. (2013). Discovering statistics using IBM SPSS statistics: Sage.

Gao, F., Luo, T., \& Zhang, K. (2012). Tweeting for learning: A critical analysis of research on microblogging in education published in 2008-2011. British Journal of Educational Technology, 43(5), 783-801.

Hammond, M. (2005). A review of recent papers on online discussion in teaching and learning in higher education. Journal of Asynchronous Learning Networks, 9(3), 9-23.

Hew, K. F. (2016). Promoting engagement in online courses: What strategies can we learn from three highly rated MOOCS. British Journal of Educational Technology, 47(2), 320-341.

Ito, M., Gutiérrez, K., Livingstone, S., Penuel, B., Rhodes, J., Salen, K., . . Watkins, S. C. (2013). Connected learning: An agenda for research and design: BookBaby.

Jonassen, D. H. (1994). Technology as cognitive tools: Learners as designers. ITForum Paper, 1, 67-80.

Junco, R., Heiberger, G., \& Loken, E. (2011). The effect of twitter on college student engagement and grades. Journal of Computer Assisted Learning, 27(2), 119-132.

Kimmons, R., Veletsianos, G., \& Woodward, S. (2017). Institutional uses of Twitter in US higher education. Innovative Higher Education, 42(2), 97-111.

Laurillard, D. (1999). A conversational framework for individual learning applied to the 'learning organisation'and the 'learning society'. Systems Research and Behavioral Science: The Official Journal of the International Federation for Systems Research, 16(2), 113-122.

Macdonald, J., \& Twining, P. (2002). Assessing activity-based learning for a networked course. British Journal of Educational Technology, 33(5), 603-618.

Macfadyen, L. P., \& Dawson, S. (2010). Mining LMS data to develop an "early warning system" for educators: A proof of concept. Computers \& Education, 54(2), 588-599.

Markel, S. L. (2001). Technology and education online discussion forums. Online Journal of Distance Learning Administration, 4.

Morris, L. V., Finnegan, C., \& Wu, S. (2005). Tracking student behavior, persistence, and achievement in online courses. Internet and Higher Education, 8(3), 221-231.

Nichols, M. (2003). A theory for eLearning. Educational Technology \& Society, 6(2), 1-10.

Norman, S. (2016). 15 Ways to use twitter in education (for students and teachers alike). Elearning industry. Retrieved from https://elearningindustry.com/15-ways-Twitter-in-education-students-teachers

Pilotti, M., Anderson, S., Hardy, P., Murphy, P., \& Vincent, P. (2017). Factors related to cognitive, emotional, and behavioral engagement in the online asynchronous classroom. International Journal of Teaching and Learning in Higher Education, 29(1), 145-153.

Prestridge, S. (2014). A focus on students' use of Twitter-their interactions with each other, content and interface. Active Learning in Higher Education, 15(2), 101-115.

Ricoy, M.-C., \& Feliz, T. (2016). Twitter as a learning community in higher education. Journal of Educational Technology \& Society, 19(1), 237.

Sclater, N., Peasgood, A., \& Mullan, J. (2016). Learning analytics in higher education. London: Jisc Accessed February, 8, 2017.

Seely Brown, J., \& Adler, R. (2008). Open education, the long tail, and learning 2.0. Educause Review, 43(1), 16-20.

Tabachnick, B. G., \& Fidell, L. S. (2007). Using multivariate statistics: Allyn \& Bacon/Pearson Education.

Thomas, M. J. (2002). Learning within incoherent structures: The space of online discussion forums. Journal of Computer Assisted Learning, 18(3), 351-366. 